\title{
THE RADIAL ARTERY FOR CORONARY ARTERY BYPASS GRAFTING: CLINICAL AND ANGIOGRAPHIC RESULTS AT FIVE YEARS
}

Christophe Acar, MD

Amhad Ramsheyi, MD

Jean-Yves Pagny, MD

Victor Jebara, MD

Pascal Barrier, MS

Jean-Noël Fabiani, MD

Alain Deloche, MD

Jean-Léon Guermonprez, MD

Alain Carpentier, MD, $\mathrm{PhD}$
Objective: The aim of this study was to assess the long-term results of use of the radial artery as a conduit for coronary artery bypass grafting. Methods: After revival of the technique in 1989, the radial artery was used as a conduit in 910 patients undergoing coronary artery bypass grafting. A complete follow-up was obtained for the first 102 consecutive patients from 4 to 7 years after the operation (mean $5.27 \pm 1.30$ years). Fifty-nine percent of the patients were receiving calcium-channel inhibitors. An electrocardiographic stress test was obtained for 51 patients, with no contraindications found. Routine follow-up angiography was performed in 50 cases, including those of all patients with symptoms. Thus 64 radial artery and 48 left internal thoracic artery grafts were followed up from 4 to 7 years after the operation (mean 5.6 \pm 1.40 years). Results: The actuarial survival was $91.6 \%$ at 5 years, and the actuarial rate of freedom from angina was $88.7 \%$ at 5 years. Four patients underwent percutaneous transluminal angioplasty during the period of follow-up, and there were no reoperations for revision of the bypass. The electrocardiographic stress test showed negative results in $\mathbf{7 3 \%}$ of cases, electrocardiographic changes alone in $\mathbf{2 1 \%}$, and clinically positive results in $6 \%$. Angiography showed that the patency rate of the radial artery grafts was $83 \%$. The patency rate of the left internal thoracic artery grafts $(n=47)$ was $91 \%$. The difference in patency could be related to the implantation sites of the grafts, mainly the circumflex artery $(51 \%)$ for the radial artery grafts and almost exclusively the left anterior descending artery (94\%) for the left internal thoracic artery. Conclusion: The use of the radial artery for coronary bypass grafting provides excellent clinical and angiographic results at 5 years. Routine use of the radial artery in combination with the left internal thoracic artery can be recommended. (J Thorac Cardiovasc Surg 1998;116: 981-9)
The use of the radial artery (RA) for coronary artery bypass grafting was first introduced by Carpentier et $\mathrm{al}^{1}$ in 1971 . At that time the study was conducted with a limited number of patients and no antispasmodic

From the Department of Cardiovascular Surgery, Hôpital Bichat and Hôpital Broussais, Paris.

Read at the Seventy-seventh Annual Meeting of The American Association for Thoracic Surgery, Washington, DC, May 4-7, 1997.

Received for publication May 6, 1998; revisions requested June 17, 1998; revisions received July 14, 1998; accepted for publication Aug 6, 1998.

Address for reprints: Christophe Acar, MD, Chirurgie Cardiovasculaire, Hôpital Bichat, 46 rue Henri Huchard, 75018 Paris, France.

Copyright $(1998$ by Mosby, Inc.

$0022-5223 / 98 \$ 5.00+0 \quad \mathbf{1 2 / 6 / 9 4 2 2 4}$ treatments were available. Postoperative follow-up angiography showed a high rate of graft failure, and the use of this conduit was completely abandoned after $1976.2,3$

Several cases in which a patent RA graft was seen after 15 years led us to reinvestigate the use of this conduit for coronary revascularization, ${ }^{4}$ and in 1989 we initiated a new study including 910 patients to date. Some modifications of the original technique were introduced with respect to the preparation of the RA and the adjunctive use of an antispasmodic drug. Early clinical and angiographic results were excellent, with a patency rate of $92 \%$ at 1 year. ${ }^{4}$ Similar results were obtained by other authors. ${ }^{5-9}$

Nevertheless, the exact outcome of the RA graft in the long term remains unknown. The aim of this study was 


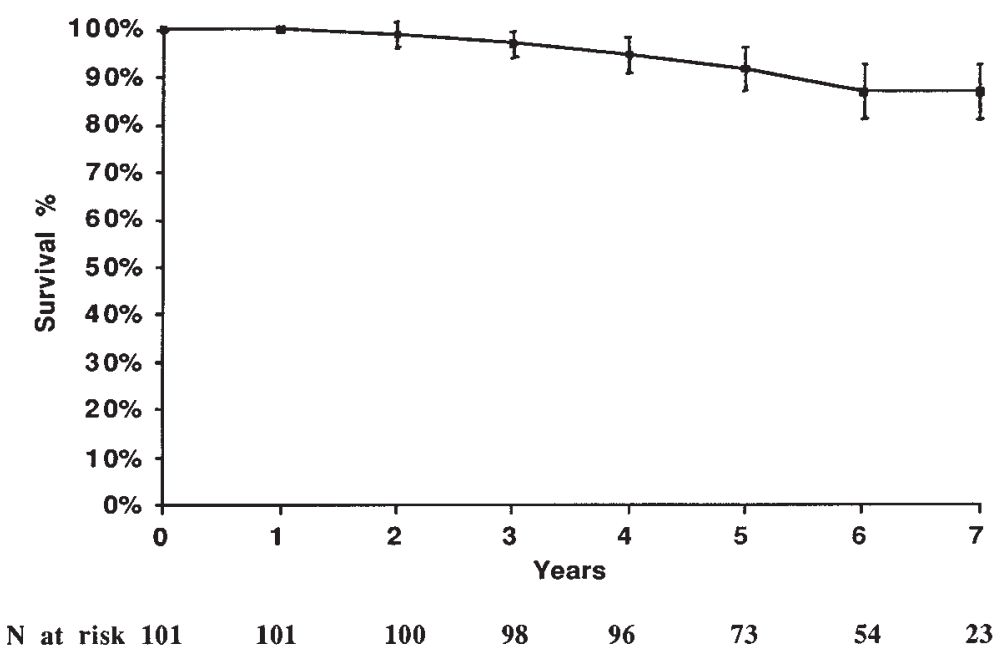

Fig 1. Actuarial survival rates after coronary artery bypass grafting with the RA.

Table I. Implantation sites of grafts

\begin{tabular}{lcc}
\hline Coronary artery & $R A(\%)$ & Left ITA $(\%)$ \\
\hline LAD & 4 & 94 \\
Diagonal & 16 & 2 \\
Circumflex & 51 & 4 \\
Right & 29 & 0 \\
\hline
\end{tabular}

to report the clinical and angiographic results of the RA graft after a 5-year period.

\section{Methods}

Between July 1989 and July 1997, 910 patients underwent coronary artery bypass grafting with the RA. To obtain the late clinical status of these patients, the cases of the first 102 consecutive patients operated on, between July 1989 and July 1993, were reviewed. Complete follow-up data were obtained. At the termination of the study period, the mean age was $67 \pm 9$ years, ranging from 51 to 83 years. Among the 102 patients, the following risk factors were noted: systemic hypertension (52\%), diabetes mellitus (30\%), and hyperlipidemia (59\%). Coronary revascularization with the RA was a reoperative procedure in $9 \%$ of the cases.

The surgical technique has been previously described. ${ }^{4,10} \mathrm{An}$ Allen test was routinely performed, and in the case of a positive result a Doppler study of the forearm was carried out to verify the patency of the ulnar artery. In the presence of a normal pulsatile flow of the ulnar artery, the RA was harvested.

Immediately before implantation, the RA conduit was catheterized with a 20 -gauge catheter and gentle hydrostatic dilatation of the graft was accomplished with a mixture of blood and papaverin to completely release the spasm. The site of proximal anastomosis was the ascending aorta (on a 4-mm hole) in $98 \%$ of cases, the left internal thoracic artery (ITA) in $1.2 \%$, and a coronary artery proximal to the stenosis (coronary-coronary bypass) in $0.8 \%$.
A calcium-channel inhibitor (diltiazem, $0.1 \mathrm{mg} / \mathrm{kg} / \mathrm{h}$ ) was administered intravenously in the intensive care unit. It was then prescribed orally $(250 \mathrm{mg} / \mathrm{d})$ in conjunction with lowdose aspirin $(100 \mathrm{mg} / \mathrm{d})$.

The average number of grafts was $2.79 \pm 0.8$ per patient (15 grafts per patient). A total of 122 RA grafts were constructed. In addition the following conduits were used for bypass: 97 pedicled left ITA grafts, 31 pedicled right ITA grafts, 10 free ITA grafts, and 23 saphenous vein grafts.

The implantation sites of both the RA grafts and the left ITA grafts are shown on Table I. An associated valve procedure was performed in 9 cases (aortic valve replacement, $\mathrm{n}=$ 6; mitral valve repair, $\mathrm{n}=3$ ).

At the completion of the follow-up, all patients underwent an interview and a physical examination. In addition, stress test electrocardiographic (ECG) examination was performed in all patients who had no contraindications.

Angiographic methods. The first 75 patients systematically underwent angiography immediately after the operation (2 weeks). In addition the first 61 patients were again catheterized at 1 year.

Late follow-up angiography was proposed for all surviving patients among the first 102 who underwent coronary artery bypass grafting with the RA. Indication for late angiography was the patient's acceptance only. Fifty follow-up angiograms were successively performed from 4 to 7 years after the operation (mean $5.6 \pm 1.10$ years). All patients with symptoms of angina or infarction underwent follow-up studies $(n=14)$. In addition, 36 symptom-free patients agreed to undergo the examination.

Statistical analysis. Clinical data (mortality rate and recurrence rate of angina) were analyzed in a time-related format by the life table method. The number of patients at risk was indicated on the curve for each interval, with error bars for 95\% confidence intervals (Figs 1 and 2). Results were reported as mean \pm standard deviation. Patency rates between groups were compared with the $\chi^{2}$ test. 


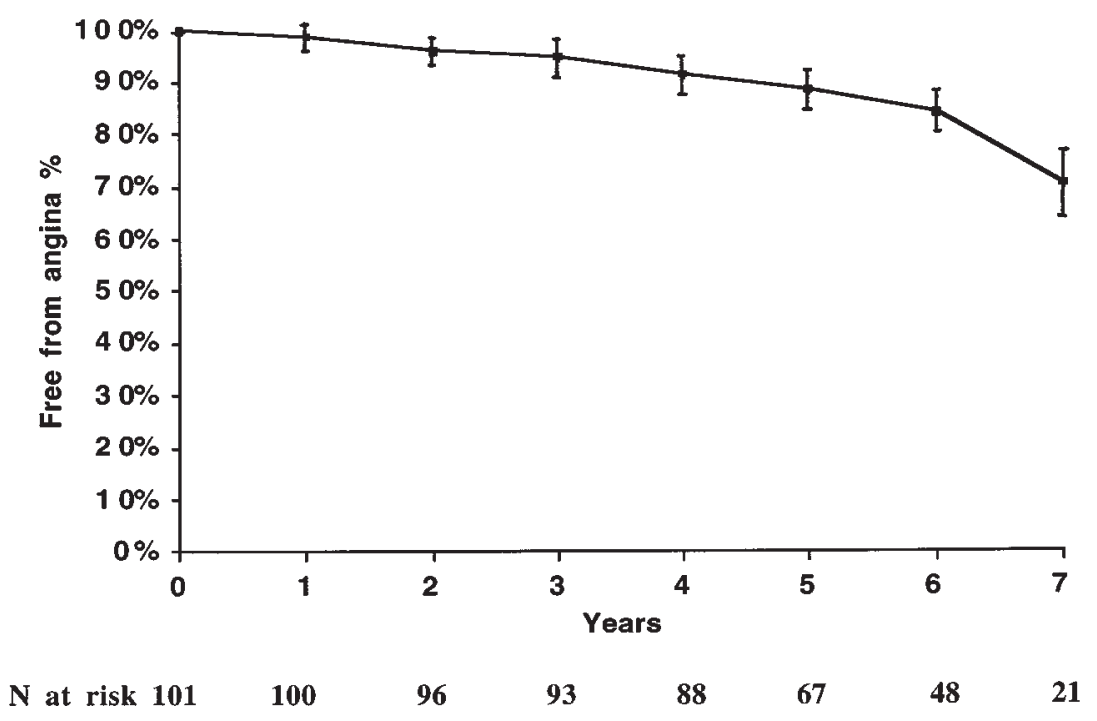

Fig 2. Actuarial freedom from angina after coronary artery bypass grafting with the RA.

\section{Results}

Among the 910 patients operated on during this time frame, no patients had contraindications to the use of the RA on the basis of blood supply study of the forearm. A positive Allen test result was noted in 36 patients (3.9\%). Verification of the ulnar artery by Doppler study showed a normal flow in all cases, and RA removal was carried out. However, intraoperative inspection of the RA revealed that this vessel was unsuitable as a graft in 18 cases for the following reasons: calcifications related to diabetes $(n=9)$, calcifications related to multifocal atheroma $(n=5)$, and chronic dissection related to catheterization of the RA during a previous operation $(n=4)$. The frequency of unusable graft findings was thus $2.0 \%$.

There were no ischemic episodes of the hand after RA removal. No morbidity was observed at the level of the forearm. In 3 cases chronic dysesthesia of the thumb was seen, but with no functional incapacity.

Clinical results. Nine patients died during the period of follow-up, 4 of cardiovascular disorders and 5 of noncardiac causes. The causes of death are listed in Table II. The actuarial survival curve, shown in Fig 1, yielded a $91.6 \% \pm 3.11 \%$ survival rate at 5 years. The 93 survivors were all reviewed after a mean follow-up of $5.27 \pm 1.30$ years (4-7 years after the operation).

At the time of follow-up the following medications had been prescribed by the cardiologists: calciumchannel inhibitors (59\%), $\beta$-blockers (30\%), and nitrates $(46 \%)$. In addition, $77 \%$ of the patients were receiving aspirin and $15 \%$ were receiving warfarin.

Thirteen patients (14\%) had occasional stable angina. One patient had an acute infarction caused by RA graft
Table II. Causes of death

\begin{tabular}{ll}
\hline Cause of death & No. \\
\hline Cardiac & \\
Congestive heart failure & 2 \\
Aortic dissection & 1 \\
Arteritis & 1 \\
Noncardiac & \\
Cerebral hemorrhage & 1 \\
Diabetic coma & 1 \\
Peritonitis & 1 \\
Pancreatic cancer & 1 \\
Suicide & 1 \\
\hline
\end{tabular}

closure. The actuarial curve of freedom from angina, shown in Fig 2, yielded $88.7 \% \pm 3.43 \%$ of patients free from angina at 5 years.

Symptoms of congestive heart failure were noted in 6 cases. Four patients underwent percutaneous transluminal angioplasty a mean of 3.2 years after the operation, and 1 patient underwent reoperation for aortic valve stenosis at 3 years (with all grafts patent). There was no reoperative coronary artery bypass grafting.

Fifty-one patients could undergo a stress test ECG examination. Contraindications for this examination were as follows: ventricular arrhythmias $(n=5)$, severe arthrosis $(n=5)$, age $>75$ years $(n=12)$, angina pectoris or recent infarction $(n=14)$, and arteritis of the lower limbs $(\mathrm{n}=6)$. The stress test was realized at $84 \%$ $\pm 2 \%$ of the theoretic maximal heart rate. The power developed during exercise was $118 \pm 6 \mathrm{~W}$.

Thirty-seven patients $(73 \%)$ had a negative stress test result. The test yielded electrically positive results with 


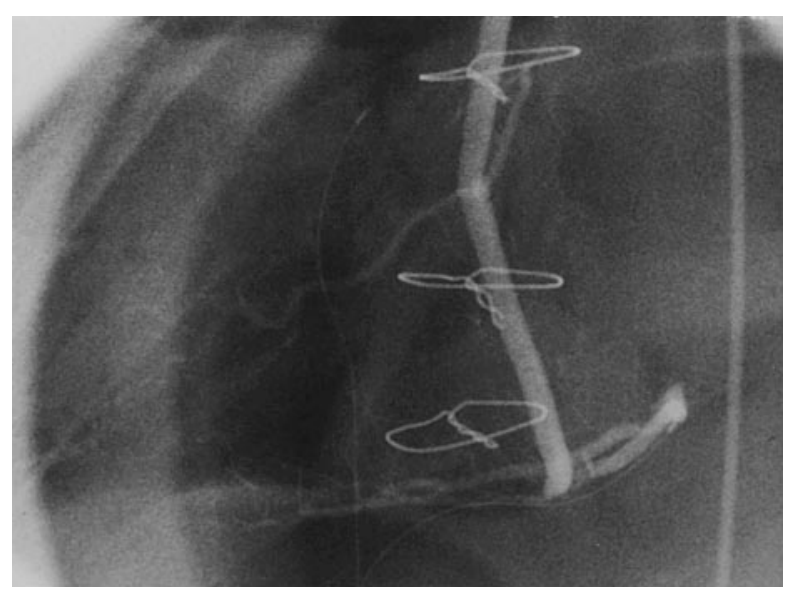

Fig 3. Sequential RA graft on the circumflex system at 5 years.

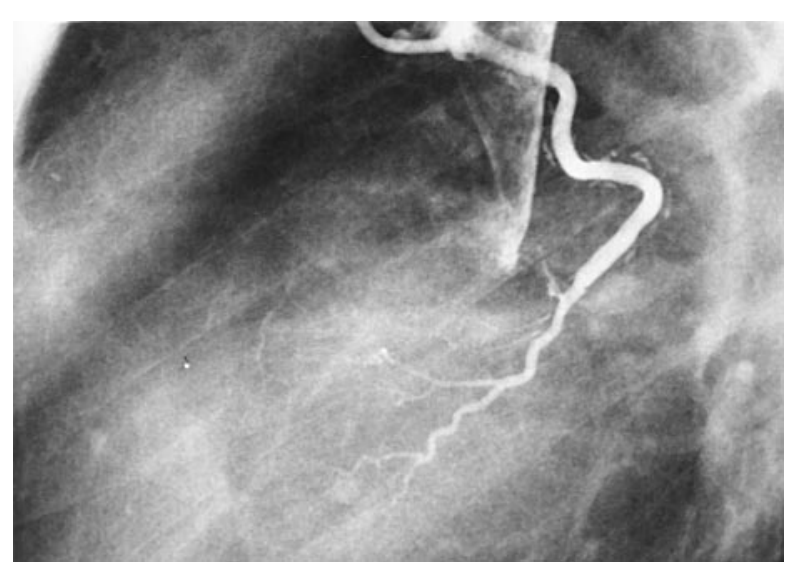

Fig 4. RA graft to diagonal artery at 7 years.

ST segment changes in 11 cases (21\%) and clinically positive results with the onset of angina in 3 cases (6\%).

\section{Angiographic results}

Early results. Early postoperative and 1-year angiographic results of this series have been previously published. ${ }^{4,10}$ Seventy-five RA grafts were opacified in the early postoperative period ( 2 weeks): 1 graft was occluded, 4 grafts showed a narrowing unrelated to the anastomotic line and most probably caused by spasm, and 70 RA grafts showed an excellent result. At 1 year, followup angiograms of 61 RA grafts were obtained and showed the following: 4 occluded RA grafts, 1 string sign, 1 low-grade stenosis, and 55 excellent results. The patency rates of the RA grafts were thus $99 \%$ in the postoperative period and $92 \%$ at 1 year, respectively.

Five-year results. Fifty patients agreed to undergo late angiography from 4 to 7 years after the operation.

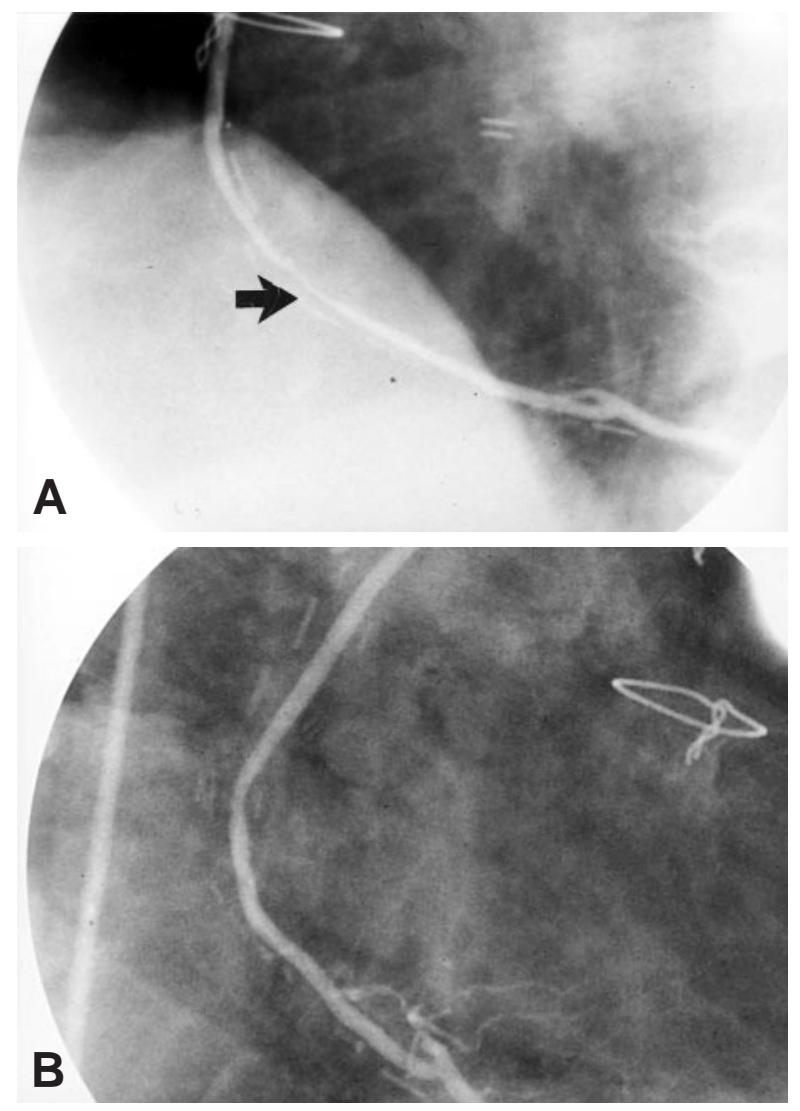

Fig 5. A, Prolonged stenosis of the midportion of RA conduit (arrow) at 3 years. B, Almost complete release of the stenosis after percutaneous transluminal coronary angioplasty.

Sixty-four RA grafts were opacified: 10 grafts were occluded, 1 graft had a string sign, and 53 grafts were perfectly functioning with no stenosis (Figs 3-6). The patency rate of these RA grafts thus was $83 \%$.

With the aim of clarifying the causes of RA graft failure $(n=11)$, careful analyses of all preoperative and postoperative angiograms were carried out. A hemodynamic factor that could have promoted graft closure was found in 8 cases. In 5 of these cases the absence of significant stenosis on the native coronary bed was probably responsible for a competitive flow, and in 3 cases the distal runoff was poor or displayed a significant stenosis. No hemodynamic explanation could be found in 3 cases.

In the meantime, angiograms of 47 pedicled left ITA grafts were obtained. Three grafts were occluded and 1 showed a high grade stenosis. The patency rate of the left ITA grafts thus was $91 \%$ at 5 years (vs $83 \%$ for the RA, $P=.19$; Fig 7).

During the follow-up period, percutaneous coronary angioplasty was performed in 4 patients at the follow- 

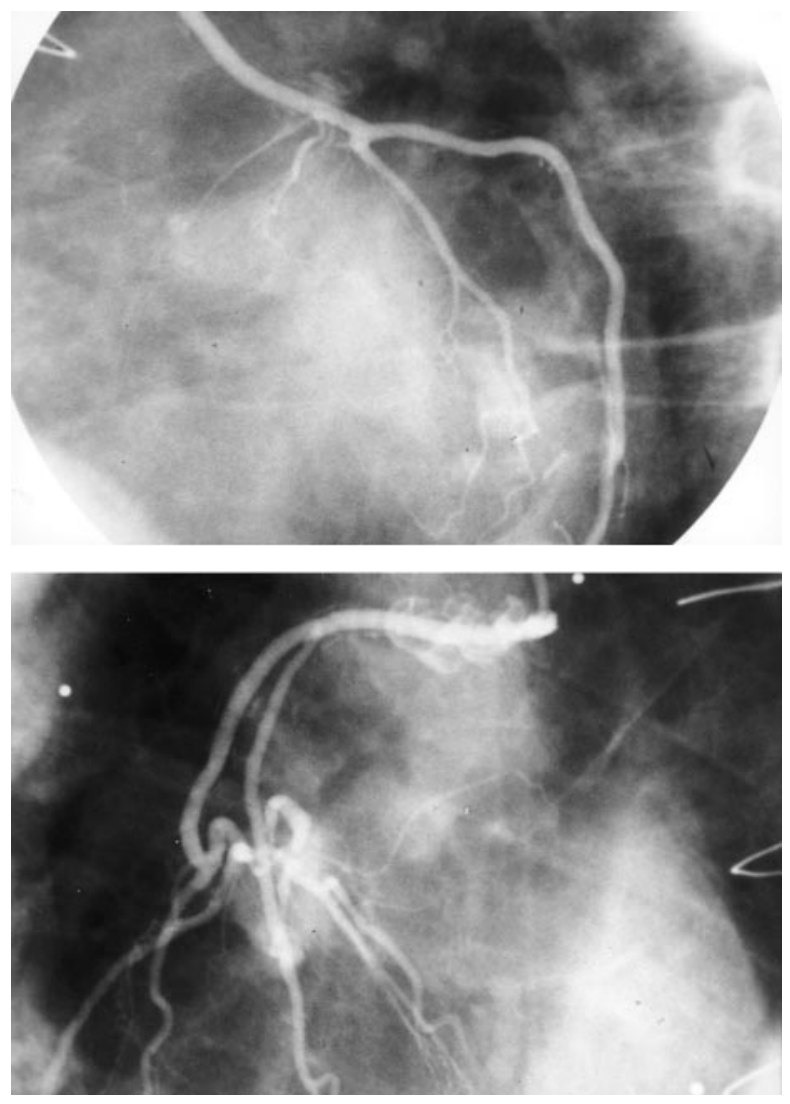

Fig 6. Sequential and Y RA grafts on 2 diagonal branches at 6 years.

ing sites: RA graft ( $n=1$, Fig 5), native coronary artery supplied by an occluded graft $(\mathrm{n}=2)$, and nongrafted coronary artery $(n=1)$. In patients with recurrence of angina, follow-up angiography at 5 years showed graft failure in 9 cases (including 5 RA grafts) and progression of coronary disease in the native vessels in 5 others, whose grafts were all patent. Among the 50 patients undergoing late angiography, 27 were receiving calcium-channel inhibitors and 23 had discontinued this treatment for at least 6 months. The numbers of occluded RA grafts in these 2 groups were 8 and 4 , respectively $\left(\chi^{2}\right.$ test $\left.P=.31\right)$.

\section{Discussion}

The clinical follow-up of patients operated on in this series confirmed the safety of RA removal. There was no significant morbidity at the site of RA graft harvesting. On rare occasions a mild dysesthesia of the thumb was observed; the mechanism of this was probably a traumatic injury to a superficial branch of the radial nerve. This complication is similar to the lesions of the saphenous nerve responsible for a dysesthesia of the

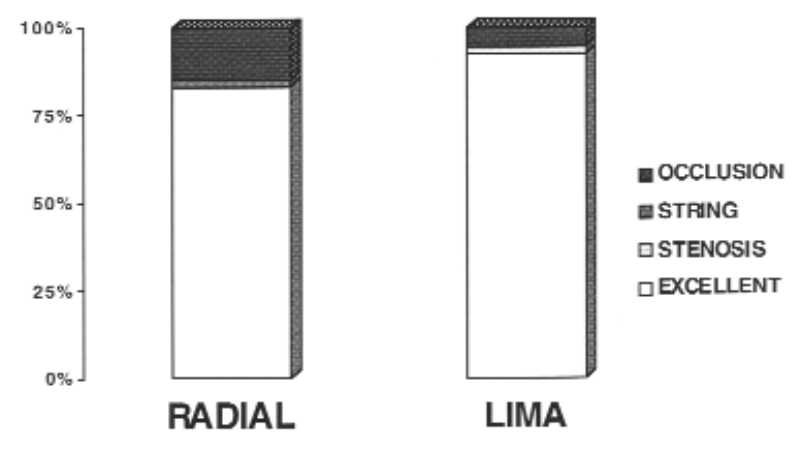

$$
\mathrm{N}=64 \quad \mathrm{~N}=47
$$

Fig 7. Five-year angiographic results of RA versus left ITA grafts. The difference in patency between these 2 arterial grafts ( $83 \%$ vs $91 \%$ ) could be related to the graft implantation sites.

superior aspect of the foot after removal of the saphenous vein in the leg. In no instance did this symptom lead to functional incapacity.

The skin incision usually healed rapidly. The occurrence of local infection was an exception, unlike in the case of the incision used for harvesting the saphenous vein at the thigh.

The quality of the RA allowed its use as a coronary artery bypass graft in almost all cases. Nevertheless, the existence of calcifications (from diabetes or multifocal atheroma) or traumatic lesions (from coronary angiography through the RA or placement of invasive blood pressure catheter) precluded the use of an RA graft in $2 \%$ of the cases. Thus particular attention must be taken when harvesting the RA in coronary reoperations because chronic dissection of this vessel resulting from pressure monitoring can be encountered. As a rule, it seems preferable to use the proximal segment of the RA in these patients in whom dissections occurred or with calcifications.

In this series no patient had contraindications for the use of an RA graft according to the result of the Allen test or the Doppler study of the ulnar flow. No signs of hand ischemia occurred, even in patients whose jobs required an extensive use of the arm (a house painter and a violinist).

The survival rates in this series were similar to those in various reports from the literature with other types of conduits. ${ }^{11}$ The actuarial rate of freedom from angina was $86 \%$ at 5 years (Figs 1 and 2).

ECG stress testing is considered a gold standard for detecting the existence of silent ischemia in coronary artery disease. In this series ECG stress testing could not be performed in all cases because of frequent contraindications related to the patient's age or associated 


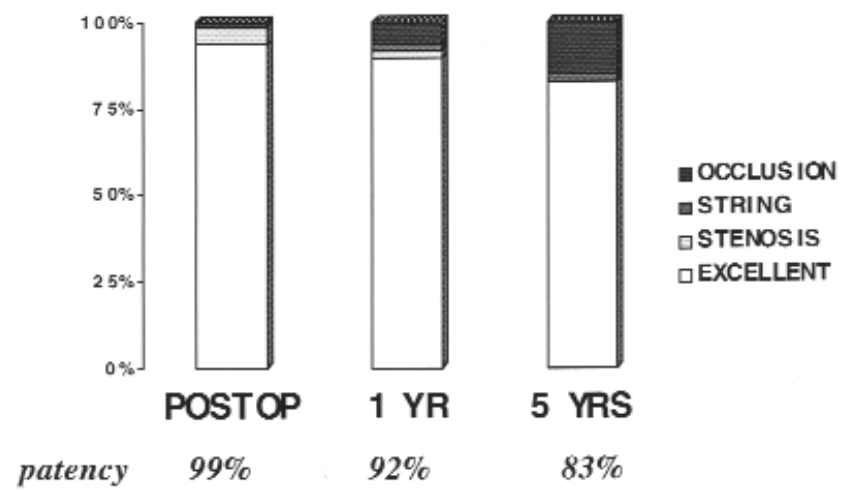

Fig 8. Fate of RA grafts. The relatively high incidence of stenosis on early postoperative (POSTOP) angiography is due to spasm and is no longer observed at 1 and 5 years.

disease. During the test heart rate frequently remained below the theoretic calculated level because a third of the patients were still receiving $\beta$-blocker agents, which restricted their response capacity to exercise. However, the power developed during exercise was satisfactory and usually exceeded $110 \mathrm{~W}$. It is not surprising to find out that the ECG stress test results were positive in 25\% of the cases, because these patients initially had triplevessel disease and their coronary disease continued to progress throughout the 5-year period of follow-up.

Follow-up angiography is the only technique capable of completely analyzing the characteristics of a conduit, with patency being the ultimate criterion of success. In this study repeated angiography was performed to analyze the fate of the RA conduits (Fig 8).

There was a relatively high incidence of spasm of the RA graft seen on postoperative angiography (Fig 8). It should be stressed that this was invariably an angiographic finding and that no patients had any clinical or ECG signs suggesting dysfunction of the RA graft. These spasms were most probably induced by the angiographic catheter selectively introduced into the RA graft. This phenomenon was observed only in the early postoperative period and was not found during the later angiography, at 1 year and at 5 years. It thus seems that the vasoreactivity of the RA is maximal in the days after the operation.

The RA is a muscular artery that has a media rich in leiomyocytes. ${ }^{12,13}$ The contraction of this small-diameter artery produces an extensive reduction in size of the lumen. The hemodynamic effects of the RA spasm are probably greater than those of a spasm involving the ITA, which has a media poor in leiomyocytes,,${ }^{14}$ or a saphenous vein, which has a much larger diameter. Consequently, it seems necessary to obtain an RA graft that is free of spasm at the time of construction of the coronary anastomoses.
As a rule, the RA is constricted at the end of the dissection. In this series the RA was catheterized and hydrostatic dilation was undertaken at a low pressure with a mixture of blood and papaverin until total release of the spasm on the whole length of the graft was obtained. Histologic studies conducted in our laboratory have shown that this maneuver is not harmful to the architecture of the arterial wall. Notably, the same technique was also used before implantation of a venous conduit.

The prescription of calcium-channel inhibitors to patients receiving ITA grafts is a widespread practice, although no study has clearly demonstrated the beneficial effects of this drug on graft patency. The same is true concerning the use of the RA graft, and we used to prescribe a calcium-channel inhibitor (diltiazem) administered intravenously in the intensive care unit and then orally. This attitude seems logical in light of the spastic characteristics of the RA graft, particularly in the postoperative period. Late follow-up of our patients revealed that the cardiologists had not always followed the initial recommendations concerning the drug therapy, however, and 5 years after the operation only $60 \%$ of the patients with RA grafts were still receiving a calcium-channel inhibitor. To our surprise, there was no difference in patency of the RA graft according to whether the patient was taking this drug.

The interpretation of angiographic data must take into consideration the implantation sites of the grafts. In fact, it has been clearly demonstrated that both the diameter of the target artery and its location (left anterior descending coronary artery [LAD] vs non-LAD site) strongly influences the patency of grafts. ${ }^{15,16}$

At 1 year the patency rate of the RA graft was $92 \%$, apparently higher than that of vein grafts constructed under the same conditions (on non-LAD coronary arteries). Indeed, recent multicenter studies have shown that the patency rate of vein grafts at 1 year was $80 \%$ 
among grafts that had not been anastomosed to the LAD. ${ }^{15-17}$

The higher incidence of early graft failure is unlikely to be related to histologic changes of the venous wall, which did not have time to take place in such a short time frame. Conversely, the superior hemodynamic characteristics of the RA graft compared with those of saphenous vein graft could account for the difference in patency. The RA has a diameter close to that of the coronary arteries, and the diameter ratio between the graft and the target vessel never exceeds $2: 1$. In addition, this graft is free of valvulae and its caliber is homogeneous throughout its whole course, with a slight decrease in diameter from the proximal to the distal end. The hemodynamic characteristics of the saphenous vein are completely different. The diameter of the vein is invariably larger, frequently leading to a major discrepancy in size with the coronary artery in which the diameter ratio can reach 5:1. Furthermore, the saphenous vein is rich in valvulae and its diameter is not constant, with abrupt changes at the level of collateral branches. The diameter of the vein increases from the proximal to the distal end. These relatively unfavorable hemodynamic characteristics probably account for the higher early occlusion rate of venous grafts when they are anastomosed to small target vessels.

At 5 years, the difference in patency between RA and venous graft is further magnified. Except in the case of 1 patient whose RA stenosis was successfully treated with percutaneous transluminal coronary angioplasty (Fig 5), no signs of graft disease were noted in this series. The 5-year patency rate of the RA (83\%) appears to be higher than that of the venous grafts reported in the literature $(55 \%$ according to Lytle et $\mathrm{al}^{18}$ ). The latter are frequently affected by graft disease, with progressive intimal hyperplasia responsible for stenosis and occlusion. ${ }^{18}$ The arterial ultrastructure of the RA graft is accustomed to a systemic pressure regimen and, as with the ITA graft, this could account for the superior late patency of the graft.

In this series the patency rate of the RA graft at 5 years was slightly lower than that of the ITA graft (Fig 7). It should be emphasized that all RA conduits were constructed on small target vessels, with half of the radial arteries anastomosed to the circumflex system and a third to the right coronary artery. Conversely, the left ITA was almost always anastomosed to the LAD. Thus the difference in patency between these 2 arterial grafts could be related to the graft implantation sites. Interestingly, in a study by Loop et $\mathrm{al}^{19}$ the ITA when used as a free graft offered the same late patency rate to that of the RA, with $84 \%$ of the free ITA grafts being patent at 5 years.
To determine the causes of RA graft occlusion, all preoperative and postoperative angiograms of patients with graft failure were carefully analyzed. The factors influencing graft patency were not specific to the RA and have been well documented for other arterial or venous conduits, whether used as free or pedicled grafts. In most cases a hemodynamic factor that could have promoted graft occlusion was observed. The absence of significant stenosis of the native coronary arteries, resulting in competitive flow, was frequently encountered. Occasionally preoperative angiograms displayed a poor or multiply stenosed distal runoff.

In conclusion, the RA for coronary bypass grafting stands the test of time and offers excellent clinical and angiographic results at 5 years. Routine use of this conduit can be recommended. Ultimately, the superiority of the RA graft with respect to the vein graft will need to be confirmed by a prospective randomized study with early and late follow-up angiography.

\section{REFERENCES}

1. Carpentier A, Guermonprez JL, Deloche A, Frechette C, Dubost C. The aorta-to-coronary radial bypass graft: a technique avoiding pathological changes in grafts. Ann Thorac Surg 1973;16:111-21.

2. Curtis JJ, Stoney WS, Alford WC, Burrus GR, Thomas CS. Intimal hyperplasia: a cause of radial artery aortocoronary bypass graft failure. Ann Thorac Surg 1975;20:628-35.

3. Fisk RL, Brooks CH, Callaghan JC, Dvorkin J. Experience with the radial artery graft for coronary bypass. Ann Thorac Surg 1976;21:513-8.

4. Acar C, Jebara VA, Portoghese M, Beyssen B, Pagny JY, Grare P, et al. Revival of the radial artery for coronary artery bypass grafting. Ann Thorac Surg 1992;54:652-60.

5. Calafiore AM, Di Giammarco G, Teodori G, et al. Radial artery and inferior epigastric artery in composite grafts: improved midterm angiographic results. Ann Thorac Surg 1995;60:517-24.

6. Dietl CA, Benoit CH. Radial artery graft for coronary revascularization: technical considerations. Ann Thorac Surg 1995;60: 102-10.

7. Chen AH, Nakao T, Brodman RF, Greenberg M, Charney R, Menegus M, et al. Early postoperative angiographic assessment of radial artery grafts used for coronary artery bypass grafting. J Thorac Cardiovasc Surg 1996;111:1208-12.

8. da Costa FD, da Costa IA, Poffo R, Abuchaim D, Gaspar R, Garcia L, et al. Myocardial revascularization with the radial artery: a clinic and angiographic study. Ann Thorac Surg 1996; 62:475-80.

9. Manasse E, Sperti G, Suma H, Canosa C, Kol A, Martinelli L, et al. Use of the radial artery for myocardial revascularization. Ann Thorac Surg 1996;62:1076-83.

10. Acar C, Jebara V, Fabiani JN, Deloche A, Carpentier A. Radial artery: surgical techniques and clinical results. In: Angelini GD, Bryan AJ, Dion R. Arterial conduits for myocardial revascularization. London: Arnold; 1996. p. 141-6.

11. Lytle BW, Cosgrove DM, Loop FD, et al. Perioperative risk of bilateral internal mammary artery grafting: analysis of 500 cases from 1971 to 1984. Circulation 1986;74:(5 Pt 2):III37-41.

12. Van Son JA, Smedts F, Vincent JG, van Lier HJ, Kubat K. 
Comparative anatomic studies of various arterial conduits for myocardial revascularization. J Thorac Cardiovasc Surg 1990;99: 703-7.

13. Acar C, Jebara V, Porthogese M, et al. Comparative anatomy and histology of the radial artery and the internal thoracic artery: implication for coronary bypass. Surg Radiol Anat 1991;13:283-8.

14. Chardigny C, Jebara V, Acar C, et al. Vasoreactivity of the radial artery: comparison with the internal mammary artery and gastroepiploic arteries with implications for coronary artery surgery. Circulation 1993;88(suppl):II115-27.

15. Goldman S, Copeland J, Moritz T, et al. Saphenous vein graft patency one year after coronary artery bypass surgery and effects of antiplatelet therapy: results of a Veterans Administration cooperative study. Circulation 1989;80:1190-7.

16. Paz MA, Lupon J, Bosch X, Pomar JL, Sanz G. Predictors of early saphenous vein aortocoronary bypass graft occlusion. Ann Thorac Surg 1993;56:1101-6.

17. Ollivier JP. Étude de la perméabilité des pontages aortocoronaires à 6 mois: étude multicentrique française. Arch Mal Coeur 1991; 84:537-42

18. Lytle BW, Loop FD, Cosgrove DM, Ratliff NB, Easley K, Taylor PC. Long-term (5 to 12 years) serial studies of internal mammary artery and saphenous vein coronary bypass grafts. J Thorac Cardiovasc Surg 1985;89:248-58.

19. Loop FD, Lytle BW, Cosgrove DM, et al. Free (aorta-coronary) internal mammary artery graft. J Thorac Cardiovasc Surg 1986; 92:827-31.

\section{Discussion}

Dr Hendrick B. Barner (St Louis, Mo). Dr Acar and associates are to be complimented for providing us with the only 5-year follow-up of the RA graft, with an impressive $83 \%$ patency rate. Although current enthusiasm for the RA has emanated from Paris throughout the world, I continue to find that some surgeons are skeptical and want to know why the RA is better now than it was before. It is important to address this concern, which has to do with the evolution of surgical technique and basic science.

We treated all conduits badly in the early 1970s by inflicting mechanical trauma during harvesting and chemical and physical injury as we attempted to overcome harvest spasm. As a consequence, the endothelium was damaged or destroyed.

It was not until Furchgott and Zawadzki reported in 1980 the existence of endothelially derived relaxing factor that we realized that the endothelium was more than a passive barrier. Subsequently, we learned that the endothelium continuously elaborates nitric oxide at a basal level and that as flow increases the associated shear stress stimulates greater production of nitric oxide.

It is true that the RA has more smooth muscle in its wall than do the other arterial conduits and that harvest spasm is therefore more intense and resistant to treatment. Although we have the pharmacologic means to overcome harvest spasm, the essence of maintaining patency in an arterial conduit is functional preservation of the endothelium so that the normal physiologic interplay of vasoactive substances is allowed to prevail and result in a functioning conduit.

Without the presence of endothelially derived nitric oxide, prostacyclin, hyperpolarizing factor, and perhaps other vasodilators, the natural tendency is for all conduits to narrow and even close because of the presence of vasoconstrictor mediators and the nature of vascular smooth muscle to contract. Additionally, nitric oxide inhibits platelet aggregation and adherence, leukocyte adherence, and scavenging of superoxide radicals.

I therefore believe that it is this evolution in science and surgery that has allowed us to arrive at this milestone in resurrection of a fallen surgical technique by a group that had the wisdom to recognize the importance of clinical observations and new knowledge and had the insight to try it again.

Dr Acar, is the small number of conduits per patient related to the fact that not all patients had triple-vessel disease? It appears that you have not used sequential anastomoses or conduit-to-conduit anastomoses in any great numbers. Do you believe that these are not appropriate techniques, or that they should only be used in special circumstances? What is your current practice with respect to short- and long-term calcium-channel blocker therapy? Have you correlated RA patency with long-term calcium-channel blocker use?

Dr Richard F. Brodman (Bronx, $N Y$ ). Following the lead of Dr Acar and associates, I have been using the RA routinely. Since November 1993 I have performed 369 consecutive coronary artery bypass graft procedures. Three hundred sixty-eight RAs were harvested in 266 patients. Ninety percent of the bypass grafts in the 266 patients were arterial, and $60 \%$ of these were performed with the RA graft. The average number of grafts per patient was 3.3 .

The complications of RA harvest have been nearly absent, and there have been no instances of hand ischemia. Our follow-up extends to $3 \frac{1}{2}$ years and is remarkably similar to that of Dr Acar and associates, although not as long. At 1, 2, and 3 years' follow-up - these data were accumulated prospectively by my nurse practitioner, Rosemary Frame, by direct communication with the patient on the anniversary of that patient's operation- $85 \%$ to $88 \%$ of the patients had no symptoms and $42 \%$ to $44 \%$ were still taking calcium-channel blockers.

I have the same initial question that Dr Barner had with respect to calcium-channel blockers. Although you have only performed recatheterization in a small number of cases, are there any differences between those patients who were taking calcium-channel blockers and those who were not?

In Dr Coltharp's discussion of your RA presentation at The Society for Thoracic Surgeons meeting in 1992, he stated that their angiographic patency rates at 5 years and 10 years were similar. Although the patency rates of $65 \%$ and then $60 \%$ reported by Coltharp are lower than the excellent patency rate at 5 years that you reported today, do you think that the 5-year patency rate of RA grafts will predict the 10-year patency rate? Are there any subtle angiographic findings in your 5year postoperative catheterizations that worry you?

Dr Francisco Diniz Affonso da Costa (Curitiba, Brazil). In Curitiba, Brazil, we have performed 218 myocardial revascularization procedures with the RA during the last 3 years. Among the first 100 cases we performed angiography before 
hospital discharge in 81 , with an early patency rate of $96 \%$. Twenty-six patients, including 3 patients with symptoms, underwent a late angiographic follow-up study between 6 and 33 months, with only 1 occlusion found. Five of these patients were studied after 12 months of follow-up. Although our protocol recommends the use of calcium channel blockers after the operation, $30 \%$ of them had discontinued the use of this medication by the time of late restudy, with no apparent adverse effects. It is our impression that the vasomotor reactivity of the RA, as demonstrated by some localized catheter-induced spasm during the time of angiography, diminishes with time. We have not observed this phenomenon in the late studies.

I have a question for Dr Acar. Although the use of a composite RA graft from the left ITA, as advocated by others, gives you some extra length to reach the extremely distal marginal branches, it seems to me that there is no advantage in terms of patency rate with this maneuver. What are your current thoughts on the site of the proximal anastomosis for the RA graft?

Dr Nitu Vasant Mandke (Mumbai, India). During the past 30 months we have performed more than 1000 RA grafts in all combinations, as individual single grafts, sequential grafts, as $\mathrm{Y}$ or T grafts, from ITAs. I do not want to present all my data, but we have encountered some problems and gone around them, and I just wanted to get some information from you.

We usually find that the RA diameter is a little bit smaller in Indian patients. Do you find any statistical relationship between the patency rate of the smaller diameter of the RA and the long-term patency? Also, in some patients we do get a small pedicle. In some patients the area surrounding the RA (available to create the pedicle) is not really big.

One of our patients had a sequential RA graft to the posterior descending artery and posterolateral branch and could not be weaned from cardiopulmonary bypass. When we recognized that this was a case of RA spasm, we had to put in an additional saphenous vein graft to the posterior descending artery and posterolateral branch. The patient could then easily be weaned from cardiopulmonary bypass. From that time forward, we started injecting a papaverine and diltiazem mixture into the pedicle or the RA, which eliminated our problems of RA spasm. Since that time we have had no such difficulties with RA grafts.

We have found that some patients older than 65 years have calcifications in the RA that can easily be seen with the naked eye. Would you discard such RAs, or can one still go ahead and use them? I ask this question because you reported that your oldest patient with RA conduit placement was 85 years old.

Dr Olivier Jegaden (Lyon, France). I want to emphasize 2 points from your results. First, you used the RA to bypass the left coronary network in $71 \%$ of the patients. Second, you showed that the 5 -year patency rate of RA was $5 \%$ or $6 \%$ lower than that of the ITA. I have 2 related questions. First, why did you not use bilateral ITA grafts in your patients? Second, for which indications do you think that RA graft can be justified as an alternative to ITA graft?
Dr Acar. Dr Barner, despite the fact that most patients had triple-vessel disease in this series, the mean number of grafts per patient was 2.8. It is our policy to construct coronary bypasses only on satisfactory target vessels whose size equals or exceeds $1 \mathrm{~mm}$. Consequently, the number of grafts seldom exceeded 4 per patient. Sequential or $Y$ graft techniques were used on rare occasions, and we favored the use of 1 graft per coronary vessel.

An important issue concerns the use of calcium-channel blockers and its relationships to late patency rate. Although we did not have enough data in this series to allow sophisticated statistical analysis, we have tried to match the cases of patients with and without calcium-channel blockers. This study failed to demonstrate any difference related to the antispasmodic treatment. It is interesting to note that we never observed any case of spasm when performing follow-up angiography beyond the first postoperative year. It may well be that the calcium-channel blocker therapy could safely be interrupted after this time frame.

Dr Brodman, it seems dangerous to extrapolate the 10-year results of the RA grafts from this study, which reports results at 5 years. It is noteworthy that the number of occluded grafts per year was the highest during the first postoperative year and decreased during the second year and beyond that time. The patency rates were $99 \%$ at 1 month, $92 \%$ at 1 year, and $83 \%$ at 5 years. There were no signs of graft disease in any patients in this series, except in the case of 1 patient who underwent percutaneous transluminal angioplasty at 3 years.

Dr da Costa mentioned the use of composite arterial grafts. We believe that the anastomosis of the RA to the ITA can sometimes be technically difficult, and we are reluctant to systematically anastomose the RA to the ITA for fear of impairing the early patency rate of the most important graft, namely the left ITA to LAD. Therefore in most cases the RA was directly anastomosed to the ascending aorta. This technique has remained reproducible and safe.

Dr Mandke raised a question concerning the patency rate of small RA vessels versus that of larger vessels. A statistical analysis in this series would require a larger number of angiograms. However, we believe that the size match between the graft and the coronary vessel is probably more important for the patency than is the size of the graft itself. In this series the size of the RA in our patients was invariably larger than the size of the coronary vessel. On the other hand, RA with calcifications or traumatic lesions should not be used for bypass.

Finally, Dr Jegaden proposed routine use of bilateral ITAs rather than a combination of the left ITA with the RA, which has been our choice. Many surgeons are reluctant to use bilateral ITA routinely because of the higher incidence of wound complications, in particular in elderly patients and those with diabetes. Although the left ITA has been shown to be an excellent graft for the LAD, the patency rate of the right ITA constructed on other target vessels is not as well established. In our practice the use of bilateral ITAs was restricted to young patients, younger than 55 years, and it would be used in a combination with the RA graft. 